\title{
Genetic Diversity Based on Morphological Traits of 19 Maize Genotypes Using Principal Component Analysis and GT Biplot
}

\author{
A. M. M. Al-Naggar ${ }^{1 *}$, M. M. Shafik ${ }^{1}$ and R. Y. M. Musa ${ }^{2}$ \\ ${ }^{1}$ Department of Agronomy, Faculty of Agriculture, Cairo University, Giza, Egypt. \\ ${ }^{2}$ Department of Agronomy, Faculty of Agriculture, Upper Nile University, South Sudan.
}

\begin{abstract}
Authors' contributions
This work was carried out in collaboration among all authors. Author AMMA designed the study, performed the statistical analysis, wrote the protocol, and wrote the first draft of the manuscript. Authors MMS and AMMA managed the literature searches. Author RYMM performed the experimental work and managed the analyses of the study. All authors read and approved the final manuscript.
\end{abstract}

Article Information

DOI: 10.9734/ARRB/2020/v35i230191 Editor(s):

(1) Dr. Rishee K. Kalaria, Navsari Agricultural University, India. Reviewers: (1) JANILSON PINHEIRO DE ASSIS, Federal Rural University of the Semi-Arid (UFERSA), Brazil. (2) Pham Thi Thu $\mathrm{Ha}$, Ton Duc Thang University, Vietnam. Complete Peer review History: http://www.sdiarticle4.com/review-history/56180

Original Research Article

Received 02 February 2020

Accepted 09 April 2020

Published 14 April 2020

\begin{abstract}
Among the phenotypic, biochemical, and molecular methods employed in assessment of genetic diversity, the phenotypic method has proven efficient for the assessment, description and classification of germplasm collections to enhance their use in maize breeding. The objectives of the present study were: $(i)$ to assess the extent of genetic diversity in a collection of Egyptian commercial maize hybrids and populations, through field evaluation under water and $\mathrm{N}$ stressed and non-stressed conditions, using morphological data based on Principle Component Analysis (PCA), (ii) to measure the genetic distance among these genotypes using UPGMA cluster analysis and (iii) to assess the relationship between grain yield and yield-related traits of maize genotypes using GTbiplot analysis. A two-year field experiment was conducted in a split-split plot design with 3 replications, where 2 irrigation regimes, three $\mathrm{N}$ rates and 19 maize genotypes occupied the main plots, sub plots and sub-sub plots, respectively. The germplasm was assessed for 21 agronomic traits. Highly significant differences $(P \leq 0.01)$ were observed among the maize hybrids and populations for all measured traits. Results of the GT biplot in the present study indicated that high
\end{abstract}

*Corresponding author: E-mail: medhatalnaggar@gmail.com, ahmedmedhatalnaggar@gmail.com; 
values of 100-Kernel weight, ears/plant, kernels/plant, kernels/row, plant height, nitrogen use efficiency, nitrogen utilization efficiency, and grain nitrogen content and short ASI could be considered reliable secondary traits for improving grain yield under stressed and non-stressed conditions. The highest genetic distance was found between G9 (SC-2055) and each of G15 (American Early Dent), G18 (Midland) or G19 (Ried Type). The Agglomerative Hierarchical Clustering based on phenotypic data assigned the maize genotypes into five groups. The different groups obtained can be useful for deriving the inbred lines with diverse features and diversifying the heterotic pools.

Keywords: Phenotypic data; PCA; GT-biplot; maize collections; clustering.

\section{INTRODUCTION}

Maize (Zea mays L.) is one of the most important cereal crops having wider adaptability under varied agro-climatic conditions. It ranks the second amongst cereal crops grown in Egypt with regard to the harvested area and production after wheat (Triticum aestivum L.). According to FAOSTAT [1], Egypt in 2017 grew 920,601 hectares and produced 7.1 million tons of grains, with an average yield of 7.72 -ton $\mathrm{ha}^{-1}$. It is consumed as food by humans and as a feed for the livestock and poultry. It is also used as basic raw material in numerous industrial products including starch, oil, protein, alcoholic beverages, food sweeteners, pharmaceutical, cosmetic, film, textile, gum, package, paper industries and so on [2]. Maize has high nutritive value as it contains 72 per cent starch, 10 per cent protein, 4.80 per cent oil, 8.50 percent fiber, 30 per cent sugar and 1.70 per cent ash [3].

The local production of maize in Egypt is not sufficient to satisfy the local consumption, which is about 16 million tons. So Egypt imports every year more than nine million tons of maize grains. To reach self-sufficiency of maize production in Egypt, efforts are devoted to increase the production via increasing the cultivated area by growing maize in the sandy soils of low waterholding capacity and deficiency in nutrients, especially nitrogen. Egypt needs to improve the productivity of maize under such conditions, i.e. develop drought and/or low- $\mathrm{N}$ tolerant maize cultivars. To start a successful breeding program for improving low $\mathrm{N}$ and/or drought tolerance, available maize germplasm should be screened for productivity and agronomic and physiological performance under such stressed and nonstressed conditions in order to identify the best genotypes that could be used directly or indirectly as suitable sources for developing tolerant hybrids to these stresses. The success of the improvement of new maize cultivars tolerant to these stresses depends on the availability of genetic variability [3]. In order to achieve this, available maize germplasm should be screened for genetic diversity. The higher the genetic diversity possessed, the greater the chances of success for developing new superior cultivars. Measuring the available genetic diversity is of utmost importance for effective evaluation and utilization of germplasm [4]. To get improved cultivars, breeders must use diverse material in their breeding programs for development of crosses and selection of heterotic inbred lines and pools [5].

Genetic diversity studies in maize are well documented by various authors, therefore providing a rationale on the importance of such studies [6-8]. Dao et al. [6] stated that genetic diversity in different populations provides and strengthens the adaptability to changing environments and market requirements. Additionally, Legesse et al. [7] cited that the importance of genetic diversity in the formation of heterotic groups for use as source materials in a breeding program. Genetic progress in yield and other traits of economic importance in any breeding program is highly dependent and influenced by the genetic variability within the breeding population [8]. Therefore, selection of the improved breeding material depends on the level of available genetic variability [8].

Both morphological and molecular methods are employed in estimating genetic diversity in germplasm collections. Although morphological evaluation is limited by effect of environment on trait expression, exhibits low heritability, is time consuming, labor intensive, requires large population size, and does not cover the genome [9], it offers an unparalleled means of identification of phenotypic variation. Morphological characterization is the first step for the assessment, description and classification of germplasm collections to enhance their use in maize breeding $[10,11]$. Phenotypic descriptors are easy to record, inexpensive and are reliable for estimating heritability $[12,13]$. For these reasons, they are highly preferred in developing 
countries, where labor is readily available at reduced cost. Phenotypic assessment has proven efficient for diversity analysis in cereal crops, including maize [14-17].

Multivariate analysis is the most popular approach for genetic variability estimation to study the patterns of variation and their genetic relationships among germplasm collections [18, 19]. The PCA and cluster analysis are preferred tools for morphological characterization of genotypes and their grouping on similarity basis based on this approach [20]. Multivariate analyses have been utilized in many countries for maize [21,22].

Although researchers investigated several traits in different environments, they usually experienced problems in assessments of these traits. The problem gets complicated in selection studies especially when there is a negative interaction between the primary trait of the experiments and the other traits [23]. Genotype main effect plus genotype $x$ environment interaction (GGE) biplot method is considered as the best method for reliable assessments in multi-environment experiments [24]. The method was developed by Yan [24] and it uses different types of biplot graphs created through adding Genotype $\times$ Environment interaction effect onto genotype main effects for the target trait. GGE biplot method allows the user to assess entire two-way data [25]. Assessments are usually performed over PC1 and PC2 axes calculated from the data of rows and columns from a two dimensional array produced by the combination of genotypes and environments in multiple environment datasets [26]. Different uses of the method were explained in detail by Yan [24]. GGE biplot method is commonly used for visual assessment of Genotype $x$ Environment interaction for grain yield of different plants in multi-environment experiments $[27,28]$. The method is also used for visual assessments of correlations among investigated traits through Genotype $\times$ Trait biplot graph [26].

The objectives of the present study were: $(i)$ to assess the extent of genetic diversity in Egyptian commercial maize hybrids and populations, through field evaluation under water and/or $\mathrm{N}$ stressed and non-stressed conditions, using morphological data based on PCA, (ii) to measure the genetic distance among these genotypes using UPGMA cluster analysis and (iii) to assess the relationship between grain yield and yield-related traits of maize genotypes across all environments using genotype $\times$ trait (GT) biplot analysis. This information will be useful for identifying genotypes for broadening the genetic base in the gene pools of maize improvement programs.

\section{MATERIALS AND METHODS}

\subsection{Plant Materials}

Seeds of 19 maize (Zea mays L.) genotypes (9 single crosses, 5 three-way crosses, and 5 openpollinated populations) collected from Agricultural Research Center (ARC) (13 genotypes), Hi-Tec Company (3 genotypes), Pioneer-Corteva Agriscience (2 genotypes), Fine Seeds Company (one genotype), were used in this study (Table 1).

\subsection{Experimental Procedure}

This study was carried out in the two successive growing seasons 2016 and 2017 at the Agricultural Experiment and Research Station of the Faculty of Agriculture, Cairo University, Giza, Egypt $\left(30^{\circ} 02^{\prime} \mathrm{N}\right.$ latitude and $31^{\circ} 13^{\prime} \mathrm{E}$ longitude with an altitude of 22.50 meters above sea level). Sowing date was April $24^{\text {th }}$ in the $1^{\text {st }}$ season (2016) and April $30^{\text {ht }}$ in the $2^{\text {nd }}$ season (2017). Sowing was done in rows; each row was $4 \mathrm{~m}$ long and $0.7 \mathrm{~m}$ width. Seeds were over sown in hills $25 \mathrm{~cm}$ apart, thereafter (after 21 days from planting and before the $1^{\text {st }}$ irrigation) were thinned to one plant/hill to achieve a plant density of about 24,000 plants/fed. Each experimental plot included two rows (plot size $=5.6 \mathrm{~m}^{2}$ ).

Evaluation in each season was carried out under 6 environments (from E1 to E6), i.e., three nitrogen levels, i.e., high-N (HN), medium-N (MN) and low-N (LN) by adding 285.6, 166.6 and 47.6 $\mathrm{kg} \mathrm{N} / \mathrm{ha}$, respectively in two equal doses in the form of Urea $46 \%$ before $1^{\text {st }}$ and $2^{\text {nd }}$ irrigations and two irrigation regimes, i.e., well-watered (WW) and water stressed (WS) conditions as follows: E1: High nitrogen-well watered (HNWW), E2: High nitrogen-water stress (HN-WS), E3: Medium nitrogen- well watered (MN-WW), E4: Medium nitrogen-water stress (MN-WS), E5: Low nitrogen-well watered (LN-WW) and E6: Low nitrogen-water stress (LN-WS).

\subsection{Experimental Design}

A split-split-plot design in randomized complete blocks arrangement with three replications was used. Main plots were allotted to two irrigation 
Table 1. Designation, origin and grain color of maize genotypes under investigation

\begin{tabular}{lllll}
\hline Genotype No. & Designation & Origin & Genetics Nature & Grain Color \\
\hline 1 & SC-10 & ARC-Egypt & Single cross & White \\
2 & 30K8 & Pioneer-Corteva & Single cross & White \\
3 & SC-101 & Fine seeds, Egypt & Single cross & White \\
4 & SC-131 & ARC-Egypt & Single cross & White \\
5 & SC-2031 & Hi-tec, Egypt & Single cross & White \\
6 & SC-30 N11 & Pioneer-Corteva & Single cross & Yellow \\
7 & SC-168 & ARC-Egypt & Single cross & Yellow \\
8 & SC-176 & ARC-Egypt & Single cross & Yellow \\
9 & SC-2055 & Hi-tec, Egypt & Single cross & Yellow \\
10 & TWC-310 & ARC-Egypt & 3-ways cross & White \\
11 & TWC-321 & ARC-Egypt & 3-ways cross & White \\
12 & TWC-1100 & Hi-tec, Egypt & 3-ways cross & White \\
13 & TWC-352 & ARC-Egypt & 3-ways cross & Yellow \\
14 & TWC- 360 & ARC-Egypt & 3-ways cross & Yellow \\
15 & American Early Dent & ARC-Egypt & Population & White \\
16 & Giza-2 & ARC-Egypt & Population & White \\
17 & Nubaria-355 & ARC-Egypt & Population & White \\
18 & Original Midland & Kensas - USA & Population & Yellow \\
19 & Reid Type Composite & USA & Population & Yellow \\
\hline
\end{tabular}

regimes, i.e. well-watered (WW) and water stressed treatments at flowering (WS). Each main plot was surrounded with an alley $(4 \mathrm{~m}$ width), to avoid water leaching between plots. Sub-plots were assigned to three nitrogen fertilizer rates, i.e. $47.6,166.6$ and $285.6 \mathrm{~kg}$ $\mathrm{N} /$ ha, respectively. Sub-sub-plots were devoted to nineteen maize genotypes.

\subsection{Water Regimes}

The following two different water regimes were used: 1. Well-watered (WW): Irrigation was applied by flooding, the second irrigation was given after three weeks and subsequent irrigations were applied every 12 days. 2. Water stress at flowering (WS): The irrigation regime was just like well watering, but the $4^{\text {th }}$ and $5^{\text {th }}$ irrigations were withheld, resulting in 24 days' water stress just before and during the flowering stage.

\subsection{Fertilization Regimes}

Nitrogen fertilization for each rate was added in two equal doses of Urea $46 \%$ before the first and second irrigation. Triple Superphosphate Fertilizer $\left(46 \% \mathrm{P}_{2} \mathrm{O}_{5}\right)$ at the rate of $30 \mathrm{~kg}$ $\mathrm{P}_{2} \mathrm{O}_{5} /$ fed (70 kg $\mathrm{P}_{2} \mathrm{O}_{5} / \mathrm{ha}$ ), was added as soil application before sowing during the preparation of the soil for planting.

Weed control was performed chemically with Stomp herbicide just after sowing and before the planting irrigation and manually by hoeing twice, the first before the first irrigation (after 21 days from sowing) and the second before the second irrigation (after 33 days from sowing). Pest control was performed when required by spraying plants with Lannate (Methomyl) 90\% (manufactured by DuPont, USA) against corn borers. All other agricultural practices were followed according to the recommendations of ARC, Egypt.

\subsection{Soil Analysis}

Physical and chemical soil analyses of the field experiments (Table 2) were performed at laboratories of Soil and Water Research Institute of ARC, Egypt.

Available soil nitrogen in $30 \mathrm{~cm}$ depth was analyzed immediately prior to sowing at the laboratories of Water and Environment Unit, ARC, Egypt and found to be 148.0 and $72.6 \mathrm{~kg} \mathrm{~N} / \mathrm{ha}$ in 2016 and 2017 seasons, respectively. Available soil nitrogen after adding nitrogen fertilizer was therefore $433.6,314.6$ and $195.6 \mathrm{~kg} \mathrm{~N} / \mathrm{ha}$, in the $1^{\text {st }}$ season and 358.2, 239.2 and $120.2 \mathrm{~kg} \mathrm{~N} / \mathrm{ha}$, in the $2^{\text {nd }}$ season for the $3 \mathrm{~N}$ treatments, i.e. $\mathrm{HN}$, $\mathrm{MN}$, and LN, respectively. The available nitrogen to each plant (including soil and added $N$ ) was calculated for each environment and found to be $7.59,5.51$ and $3.42 \mathrm{~g} \mathrm{~N} /$ plant in the first season and $6.27,4.19$ and $2.10 \mathrm{~g} \mathrm{~N} /$ plant in the second season, with an average across the two seasons of $6.93,4.85$ and $2.76 \mathrm{~g} \mathrm{~N} /$ plant for the three $\mathrm{N}$ treatments, respectively.

\subsection{Meteorological Data}

The required weather data for the experimental site through the two growing seasons were 
obtained from Central Lab for Agricultural Climate, Agricultural Research Center at Giza, Governorate, Egypt (Table 3).

\subsection{Morphological Data Recorded}

1-Days to $50 \%$ tasselling (DTA), 2-Days to $50 \%$ silking (DTS), 3-Anthesis-silking interval (ASI), 4Plant height $(\mathrm{PH})$, 5-Ear height $(\mathrm{EH})$, 6Chlorophyll concentration index (CCI) by Chlorophyll Concentration Meter, Model CCM-200, USA (available on line at: http://www.apogeeinstruments.co.uk/apogeeinstruments-chlorophyll-content-meter-technicalinformation/), 7-Number of ears plant-1 (EPP), 8Number of rows ear $^{-1}$ (RPE), 9-Number of kernels row $^{-1}$ (KPR), 10-Number of kernels plant $^{-1}$ (KPP), 11-100-kernel weight (HKW) (g), 12-Grain yield plant $^{-1}$ (GYPP) (g): (adjusted at $15.5 \%$ grain moisture), 13-Economic nitrogen use efficiency (NUEe) $(\mathrm{g} / \mathrm{g})$ as follows: $\mathrm{NUEe}=\mathrm{GDM} / \mathrm{Ns}$, where $\mathrm{GDM}=$ grain dry matter, Ns = available soil-N/plant, 14-Grain nitrogen content (GN) (in g), 15-Grain nitrogen utilization efficiency $\left(\mathrm{NUTE}_{\mathrm{g}}\right)(\mathrm{g} / \mathrm{g})$ as follows: NUTEg =
(GDM/GN), 16-Grain protein content (GPC) in \%, 17-Grain starch content (GSC) in \%, 18-Grain oil content (GOC) in \%, 19-Grain ash content (GAC) in \%, 20-Grain fiber content (GFC) in \% and 21Grain moisture content (GMC) in \%. The grain quality traits (GPC, GSC, GOC, GAC, GFC and GMC) were measured in both seasons, on samples taken from the grain bulk of each maize genotype by using INSTALAB 600 Near Infrared (NIR) Product Analyzer manufactured by DICKEY-john Corporation, Auburn, Illinois, USA.

\subsection{Biometrical Analysis}

Analysis of variance of the split-split-plot design each year was computed on the basis of individual plot observation using the MIXED procedure of MSTAT $®$. A combined analysis of variance of the split-split-plot design across the two years was also performed if the homogeneity test was non-significant. LSD values were calculated to test the significance of differences between means according to Steel et al. [29].

Table 2. Soil analysis at 0-30 cm depth in the experimental fields at Giza in 2016 and 2017 growing seasons

\begin{tabular}{|c|c|c|}
\hline Soil characteristics & 2016 season & 2017 season \\
\hline \multicolumn{3}{|c|}{ Physical analysis } \\
\hline Silt \% & 36.4 & 42.55 \\
\hline Clay $\%$ & 305.3 & 36.15 \\
\hline Fine sand \% & 22.8 & 13.35 \\
\hline Coarse sand \% & 5.5 & 7.95 \\
\hline Soil Type & Clay loam & Clay loam \\
\hline \multicolumn{3}{|c|}{ Chemical analysis } \\
\hline $\mathrm{pH}$ (paste extract) & 7.92 & 7.95 \\
\hline $\mathrm{EC}\left(\mathrm{dSm}^{-1}\right)$ & 1.66 & 2.8 \\
\hline $\mathrm{SP}$ & 62.5 & 61.5 \\
\hline $\mathrm{CaCO}_{3} \%$ & 7.7 & 4.8 \\
\hline Soil bulk density $\mathrm{g} \mathrm{cm}^{-3}$ & 1.2 & 1.15 \\
\hline \multicolumn{3}{|c|}{ Soluble anions (mEqu/l) } \\
\hline $\mathrm{HCO}_{3}$ & 0.71 & 8 \\
\hline $\mathrm{Cl}$ & 13.37 & 12.75 \\
\hline $\mathrm{SO}_{4}$ & 0.92 & 7.25 \\
\hline \multicolumn{3}{|c|}{ Soluble cations (mEqu/l) } \\
\hline $\mathrm{Ca}^{++}$ & 4.7 & 12.04 \\
\hline $\mathrm{Mg}^{++}$ & 2.2 & 7.66 \\
\hline $\mathrm{Na}^{+}$ & 8.0 & 8.09 \\
\hline $\mathrm{K}^{+}$ & 0.1 & 0.197 \\
\hline \multicolumn{3}{|c|}{ Available nutrients (mg/kg) } \\
\hline $\mathrm{N}$ & 371 & 182 \\
\hline$P$ & 6.35 & 8.86 \\
\hline $\mathrm{K}$ & 398 & 409 \\
\hline $\mathrm{Zn}$ & 4.34 & 6.55 \\
\hline $\mathrm{Mn}$ & 9.08 & 10.12 \\
\hline $\mathrm{Fe}$ & 10.14 & 15.2 \\
\hline
\end{tabular}


Table 3. Meteorological data during the two growing seasons of the experiment

\begin{tabular}{|c|c|c|c|c|c|c|}
\hline \multirow[t]{2}{*}{ Month } & \multicolumn{3}{|c|}{ Temperature } & \multirow[t]{2}{*}{ RH\% } & \multirow{2}{*}{$\begin{array}{l}\text { Wind speed } 2 \mathrm{~m} \\
(\mathrm{~m} / \mathrm{sec})\end{array}$} & \multirow[t]{2}{*}{ Sunshine duration (hr) } \\
\hline & Max. $\left({ }^{\circ} \mathrm{C}\right)$ & Min. $\left({ }^{\circ} \mathrm{C}\right)$ & Aver. $\left({ }^{\circ} \mathrm{C}\right)$ & & & \\
\hline & \multicolumn{6}{|c|}{2016} \\
\hline May & 34.6 & 19.1 & 28.9 & 38.7 & 3.4 & 13.4 \\
\hline June & 38.6 & 22.5 & 33.5 & 31.7 & 2.0 & 13.9 \\
\hline July & 36.6 & 24.3 & 32.6 & 46.3 & 2.1 & 13.8 \\
\hline \multirow[t]{2}{*}{ August } & 37.2 & 23.8 & 32.5 & 44.3 & 3.5 & 13.0 \\
\hline & \multicolumn{6}{|c|}{2017} \\
\hline May & 34.6 & 19.4 & 29.3 & 34.0 & 2.0 & 13.4 \\
\hline June & 36.7 & 16.0 & 23.3 & 23.3 & 2.0 & 13.9 \\
\hline July & 38.2 & 24.5 & 33.5 & 42.3 & 1.6 & 13.8 \\
\hline August & 37.1 & 24.6 & 32.5 & 46.3 & 2.0 & 13.1 \\
\hline
\end{tabular}

\subsection{Morphological Evaluations}

The best use of the information contained in the data for morphological characterization is an important issue in plant breeding. To display the genetic variability among maize genotypes, a Genotype $\times$ Trait biplot (GT biplot) of standardized data was applied. To generate a GT biplot [30], the genotype by trait two-way table of data was first trait-standardized. The standardization is necessary to remove the units, because different traits use different units. The trait-standardized table (data standardized) was then decomposed into principal components (PC). The first two PC (PC1 and PC2) were used to generate a GT biplot. PC1 and PC2 were scaled so that values are symmetrically distributed between the genotype scores and trait scores. A genotype by trait biplot is constructed by plotting the PC1 scores against the PC2 scores for each genotype and each trait. The biplot technique provides a powerful tool for data analysis of genotype $\times$ trait data in individual environments and can be used to visualize the genetic correlations among traits and evaluation of the genotype on the basis of multiple traits [31]. The GT biplot software XLSTAT [32] was used for all calculations.

\subsection{Cluster Analysis of Morphological Data}

Data for all the traits averaged across stressed and non stressed environments were used to develop dendrograms of phenotypic variation for the 19 genotypes. Principal component analysis was computed using XLSTAT software [32]. Agglomerative hierarchical clustering (AHC) analysis was performed using XLSTAT [32]. Based on normalized Euclidean distance matrices with the complete linkage method and dendrograms were constructed by XLSTAT [32]. GGE biplot could be used for all types of two-way data set such as genotypes with multiple traits. Yan and Rajcan [33] used the genotype by trait (GT) biplot, which is an application of the GGE biplot to study the genotype by trait data. Because the traits were measured in different units, the biplot procedure was generated using the standardized values of the trait means.

\section{RESULTS}

\subsection{Phenotypic Identification and Varia- tion}

Mean squares (Table 4) due to genotypes from analysis of variance of split-split plot design across two years were significant $(P \leq 0.01)$, indicating significant differences among maize genotypes (hybrids and populations) for all studied traits. Coefficient of variation (CV) was generally very low $(<10 \%)$ for all studied traits, except for ASI, and three of grain quality traits (GMC, GOC and GFC), which were 32.8, 20.67, 16.69 and $21.92 \%$, respectively, indicating good accurcy of the experiment.

The variability among maize genotypes expressed by phenotypic coeffiecient of variatiov (PCV) was the highest for anthesis-silking interval (ASI) followed by NUE (85.6\%), GYPP $(77.7 \%)$, GOC $(60.0 \%)$, GFC $(57.5 \%), \mathrm{CCl}$ $(49.4 \%)$ and KPP $(36.9 \%)$ traits, while the lowest PCV was exhibited by GSC (7.0\%), GMC (8.6\%), DTS $(11.3 \%)$, and DTA (12.1\%).

Range of grain yield/plant was between 95.6 to $216.5 \mathrm{~g}$ with an average of $146.5 \mathrm{~g}$ (Table 4). The single cross hybrid SC-101 (G3) had the highest grain yield, the highest 100-kernel 
weight $(41.78 \mathrm{~g})$, grain starch $(69.68 \%)$ and moisture content $(11.08 \%)$ and the highest NUTE $(44.64 \mathrm{~g} / \mathrm{g})$. Days to $50 \%$ anthesis ranged between 58.6 and 68.7 with an average of 62.8 . Days to $50 \%$ silking ranged between 62.8 and 73.2 with an average of 66.8. Anthesis silking interval ranged from 2.8 to 6.7 day with an average of 4 day. Genotype G6 (SC-30N11) had the latest anthesis (68.7 day) and silking (73.2 day), the tallest plant $(276.6 \mathrm{~cm})$, the highest ear position $(141.69 \mathrm{~cm})$, the highest chlorophyll concentration $(22.08 \%)$, the highest number of ears/plant (1.167), the highest grain nitrogen $(2.611 \mathrm{~g})$, but the lowest number of kernel/row, lowest NUE $(72.44 \mathrm{~g} / \mathrm{g})$, and the lowest grain moisture content $(10.3 \%)$.

The genotype G2 (SC-30K8) had the highest grain oil content $(4.00 \%)$, the highest NUE (96.76 $\mathrm{g} / \mathrm{g}$ ) and the highest kernels/row (44.12) but has the lowest grain protein content $(6.60 \%)$. The genotype G13 (TWC-352) had the highest number of rows/ear (15.66) and the shortest plant $(218.4 \mathrm{~cm})$. The highest protein content in the grain $(9.49 \%)$ was shown by the genotype G7 (SC-168). The genotype G9 (SC-2055) had the highest number of kernels/plant (675.4) and the highest grain ash content (11.82\%).

\subsection{Principal Component Analysis}

To display the genetic variability among maize genotypes, a principal component analysis of standardized data was applied to display maize trait relationships, and its application in genotype characterization and comparison (Table 5). Because different traits use different units, the data standardization is necessary to remove the units. Principal components, PC1 and PC2 were scaled so that values are symmetrically distributed between the genotype scores and trait scores. A genotype by trait biplot is constructed by plotting the PC1 scores against the PC2 scores for each genotype (19) and each trait (21). The genotype by trait biplot effectively reveals the interrelationships among maize traits (Fig. 1). It also provides a tool for visual comparison among genotypes based on multiple traits. The results of the genotype by trait biplot, explained $57.91 \%$ of the total variation, and are a good approximation of the total variation of the standardization data.

Table 4. Summary statistics for 21 phenotypic attributes of 19 maize genotypes evaluated in the field across six environments (2 irrigation regimes $x 3 \mathrm{~N}$ levels) and two seasons

\begin{tabular}{lllllllll}
\hline Trait & Minimum & Maximum & Mean & $\begin{array}{l}\text { LSD05 } \\
\text { (Genotype) }\end{array}$ & CV\% & $\mathbf{R}^{2}$ & $\begin{array}{l}\text { MS } \\
\text { (Genotype) }\end{array}$ & $\begin{array}{l}\text { PCV } \\
\%\end{array}$ \\
\hline DTA & $58.6(18,19)$ & $68.7(6)$ & 62.8 & 0.83 & 2.9 & 0.89 & $* *$ & 12.1 \\
DTS & $62.8(3,16)$ & $73.2(6)$ & 66.8 & 0.91 & 3.0 & 0.909 & $* *$ & 11.3 \\
ASI & $2.8(5)$ & $6.7(15)$ & 4.0 & 0.6 & 32.8 & 0.782 & $* *$ & 85.6 \\
PH (cm) & $218.4(13)$ & $276.6(6)$ & 242.1 & 7.56 & 6.7 & 0.788 & $* *$ & 20.2 \\
EH (cm) & $96.5(18)$ & $141.69(6)$ & 114.6 & 5.09 & 9.6 & 0.729 & $* *$ & 25.1 \\
CCI (\%) & $13.05(8)$ & $22.08(6)$ & 15.8 & 0.68 & 9.3 & 0.962 & $* *$ & 49.4 \\
EPP & $0.843(15)$ & $1.167(6)$ & 0.982 & 0.02 & 5.3 & 0.927 & $* *$ & 27.7 \\
RPE & $11.5(5)$ & $15.66(13)$ & 13.8 & 0.28 & 4.4 & 0.896 & $* *$ & 23.8 \\
KPR & $31.90(6)$ & $44.12(2)$ & 39.66 & 0.2 & 3.9 & 0.951 & $* *$ & 25.7 \\
KPP & $479.7(15)$ & $675.4(9)$ & 534.5 & 7.9 & 3.2 & 0.988 & $* *$ & 36.9 \\
HKW (g) & $25.36(19)$ & $41.78(3)$ & 32.23 & 1.18 & 7.9 & 0.83 & $* *$ & 32.1 \\
GYPP (g) & $95.6(19)$ & $216.5(3)$ & 146.5 & 3.42 & 5.4 & 0.992 & $* *$ & 77.7 \\
GN (g) & $1.179(19)$ & $2.611(6)$ & 1.751 & 0.08 & 10.4 & 0.973 & $* *$ & 34.1 \\
NUEe (g/g) & $72.44(6)$ & $96.76(2)$ & 83.88 & 3.92 & 6.2 & 0.995 & $* *$ & \\
NUTEg (g/g) & $19.71(19)$ & $44.64(3)$ & 30.2 & 1.04 & 9.9 & 0.824 & $* *$ & 85.6 \\
GMC (\%) & $10.3(6)$ & $11.08(3)$ & 10.64 & 0.21 & 20.7 & 0.815 & $* *$ & 30.8 \\
GPC (\%) & $6.60(2,4)$ & $9.49(7)$ & 7.59 & 0.59 & 4.2 & 0.918 & $* *$ & 8.6 \\
GOC (\%) & $2.07(3)$ & $4.00(2)$ & 3.04 & 0.29 & 16.7 & 0.739 & $* *$ & 34.2 \\
GSC (\%) & $64.56(9)$ & $69.68(3)$ & 66.86 & 0.78 & 2.5 & 0.773 & $* *$ & 60.0 \\
GFC (\%) & $1.12(3)$ & $2.12(19)$ & 1.72 & 0.17 & 21.9 & 0.795 & $* *$ & 7.0 \\
GAC (\%) & $8.85(14)$ & $11.82(9)$ & 10.36 & 0.34 & 7.2 & 0.839 & $* *$ & 57.5 \\
\hline Values are followed by genotype (G) No. in parenthesis. MS Mean squares from ANOVA. CV=coefficient of variation, &
\end{tabular}


Table 5. Principal component analysis (PCA) for morphological data, combined across all environments

\begin{tabular}{|c|c|c|c|c|c|c|c|}
\hline Trait & PC1 & PC2 & PC3 & PC4 & PC5 & PC6 & PC7 \\
\hline Days to anthesis & 0.53 & -0.58 & -0.20 & -0.42 & -0.36 & 0.11 & -0.05 \\
\hline Days to silking & 0.29 & -0.74 & -0.22 & -0.45 & -0.23 & 0.10 & 0.04 \\
\hline Anthesis silking interval & -0.71 & -0.36 & -0.05 & -0.04 & 0.39 & -0.05 & 0.25 \\
\hline Plant height & 0.69 & -0.30 & -0.14 & -0.30 & 0.11 & -0.46 & -0.04 \\
\hline Ear height & 0.63 & -0.58 & -0.29 & -0.29 & -0.05 & -0.12 & 0.06 \\
\hline Chlorophyll Con. Index & 0.34 & -0.64 & -0.14 & 0.26 & 0.25 & 0.51 & 0.00 \\
\hline Ears/plant & 0.81 & -0.33 & -0.04 & 0.33 & -0.11 & 0.16 & -0.18 \\
\hline Rows/ear & -0.75 & -0.21 & 0.30 & 0.41 & -0.25 & -0.12 & 0.08 \\
\hline Kernels/row & 0.45 & 0.42 & 0.59 & -0.39 & 0.07 & -0.03 & -0.16 \\
\hline Kernels/plant & 0.33 & -0.03 & 0.79 & 0.30 & -0.26 & -0.02 & -0.23 \\
\hline 100 Kernel weight & 0.81 & 0.20 & -0.17 & -0.27 & 0.34 & 0.02 & 0.05 \\
\hline Grain yield/plant & 0.87 & 0.28 & 0.07 & 0.34 & 0.15 & -0.05 & 0.05 \\
\hline Grain nitrogen & 0.78 & -0.13 & -0.26 & 0.50 & 0.16 & -0.14 & -0.02 \\
\hline NUTE & 0.34 & 0.63 & 0.57 & -0.28 & -0.04 & 0.19 & 0.12 \\
\hline NUE & 0.87 & 0.28 & 0.07 & 0.34 & 0.15 & -0.05 & 0.05 \\
\hline Moisture\% & 0.15 & 0.83 & -0.19 & 0.05 & -0.25 & -0.14 & 0.05 \\
\hline Protein\% & -0.34 & -0.58 & -0.55 & 0.31 & -0.03 & -0.14 & -0.18 \\
\hline Oil\% & 0.08 & -0.63 & 0.74 & -0.05 & 0.15 & -0.04 & 0.02 \\
\hline Starch\% & -0.03 & 0.84 & -0.45 & -0.14 & 0.06 & 0.15 & -0.06 \\
\hline Fiber\% & -0.56 & -0.31 & 0.46 & -0.24 & 0.41 & -0.05 & -0.33 \\
\hline Ash\% & 0.37 & -0.52 & 0.66 & 0.12 & -0.10 & -0.05 & 0.33 \\
\hline Eigenvalue & 6.87 & 5.30 & 3.45 & 1.97 & 1.02 & 0.68 & 0.46 \\
\hline Variability \% & 32.69 & 25.22 & 16.41 & 9.37 & 4.85 & 3.24 & 2.21 \\
\hline Cumulative \% & 32.69 & 57.91 & 74.32 & 83.69 & 88.54 & 91.78 & 93.99 \\
\hline
\end{tabular}

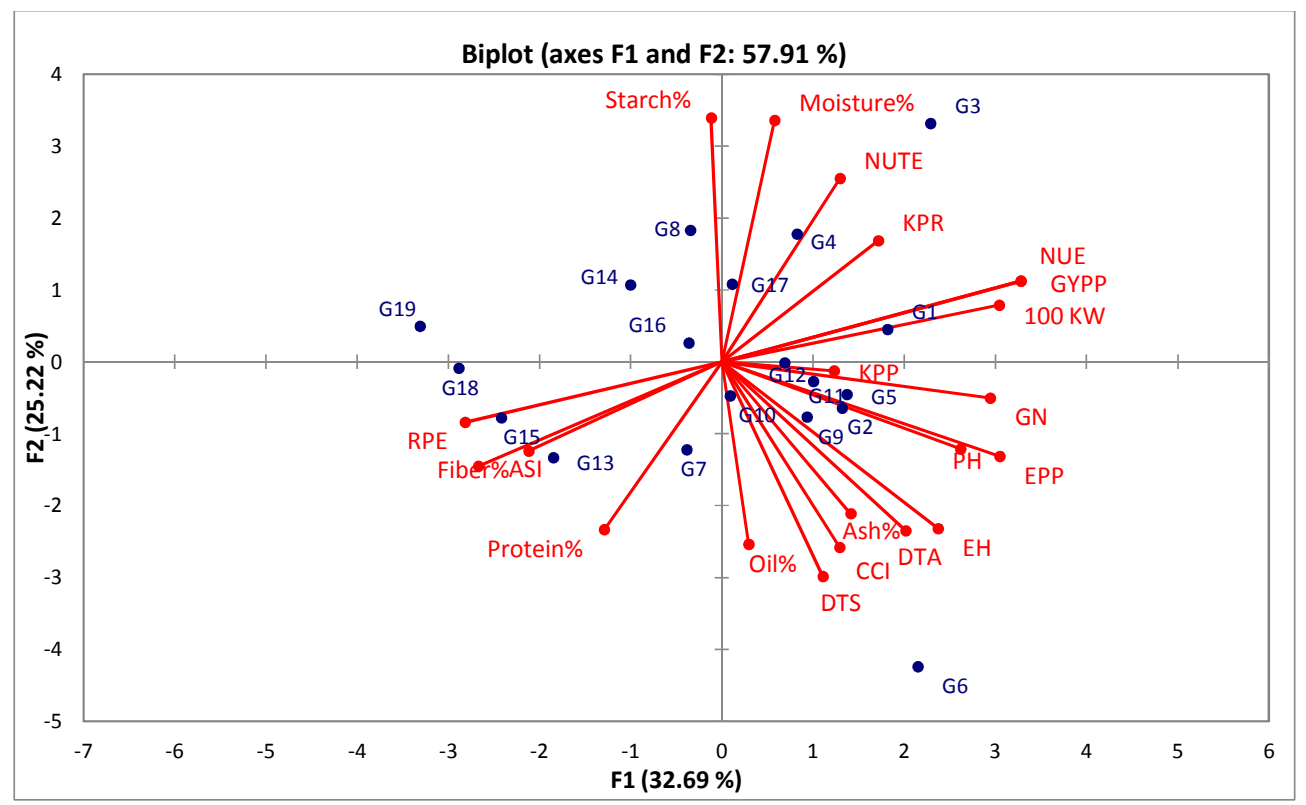

Fig. 1. Genotype by trait biplot illustrating the relationship between PC1 and PC2 for 19 genotypes and 21 traits of maize

Based on PC1 and PC2, grain yield/plant, NUE followed by 100 -kernel weight, ears/plant, rows/ear, grain $\mathrm{N}$, anthesis-silking interval, plant height, ear height, grain fiber content, grain 
starch content, grain moisture content had relatively long vectors, suggesting that there was relatively large variation among genotypes. In other words, they show large variation among the 19 genotypes studied, suggesting that they are the most discriminator of the morphological data under study. On the contrary, kernels/row, kernels/plant, grain ash content and grain oil content were the least discriminator, based on both PC1 and PC2 (Table 5 and Fig. 1). Grain yield/plant, followed by 100-kernel weight, ears/plant, rows/ear, grain $\mathrm{N}$, anthesis-silking interval, plant height, ear height and grain fiber content, grain starch content, grain moisture content based on PC1 only, kernels/row, kernels/plant, grain ash content and grain oil content based on PC2 only are the most discriminator of the studied morphological traits.

Fig. 1 showed four groups of traits versus four groups of genotypes, namely GYPP, NUE, KPR, NUTE, 100-KW and GMC for the genotypes G3, G4, G1 and G17 in the first group, GSC for the genotypes G8, G14, G16 and G19 in the second group, RPE, GFC, $\mathrm{ASI}$ and, GPC for the genotypes G7, G13, G15 and G18 in the third group, DTA, DTS, EPP, EH, PH, GN, CCl, GAC, $\mathrm{KPP}$ and $\mathrm{GOC}$ for the genotypes $\mathrm{G} 2, \mathrm{G} 5, \mathrm{G} 6$, G9, G10, G11 and G12 in the $4^{\text {th }}$ group.

The above mentioned four groups of genotypes were characterized by high values in GYPP, NUE, 100-KW, KPR, NUTE and grain moisture $\%$ traits for the first group, grain starch content for the $2^{\text {nd }}$ group, grain protein content, GFC, GAC, ASI, and RPE for the $3^{\text {rd }}$ group and days to anthesis, DTS, EPP, EH, PH, GN, CCl, GAC, KPP and GOC for the $4^{\text {th }}$ group (Fig. 1).

The traits pair GYPP and NUE had an angle of zero, indicating a perfect correlation of +1 . Traits of each group had acute $\left(<90^{\circ}\right)$ angles between them, indicating that their variation were similar, so each trait inside a specific group can be recorded instead of the other trait in the same group (GYPP, NUE, KPR, NUTE, 100-KW and GMC in the $1^{\text {st }}$ group, RPE, GFC, ASI and, GPC in the $3^{\text {rd }}$ group and DTA, DTS, EPP, EH, PH, $\mathrm{GN}, \mathrm{CCl}, \mathrm{GAC}, \mathrm{KPP}$ and GOC in the $4^{\text {th }}$ group). Trait pairs GYPP or NUE vs CCI, DTS and GAC, GMC vs KPP, NUTE vs EPP or PH, 100-KW vs DTS, GN vs GPC, GAC vs RPE, ASI or GFC vs DTA had a near-right angle, indicating that variation of one trait was more or less independent of the other trait (near zero correlation). On the contrary, GYPP or NUE vs
(RPE, GFC, GPC, GOC, ASI) NUTE vs (EH, DTA, GAC, CCI, DTS, GOC, GPC) and GMC or GSC vs (GN, EPP, PH, EH, DTA, GAC, CCl, DTS, GOC) had obtuse $\left(>90^{\circ}\right)$ angles, indicating that their variation was in opposite directions (negative correlation). Trait pairs GYPP (NUE) vs RPE, NUTE vs GPC and GSC vs GOC had an angle of $180^{\circ}$ representing a perfect negative correlation of -1 . Trait pairs GYPP (or NUE) vs $\mathrm{CCl}$, DTS and GAC had an angle of $90^{\circ}$ indicating no $(0)$ correlation.

The trait pairs GYPP or NUE vs ASI and GFC, $100-\mathrm{KW}$ vs RPE, GSC vs GOC, NUTE vs GPC and KPR vs GPC had an angle near $180^{\circ}$, indicating a correlation close to -1 (complete negative correlation). An angle near to zero indicates a correlation near to +1 such as between GYPP and NUE, EPP and PH, KPP and GN, ASI and GFC, GYPP or NUE and 100$\mathrm{KW}$.

\subsection{Dissimilarity Euclidean Coefficients Based on Phenotypic Traits}

The dissimilarity Euclidean coefficients among the 19 maize genotypes, based on phenotypic traits ranged from 13.7 to 206.1 with an average of 84.39 (Table 5).

Dissimilarity Euclidean distances showed that G9 (SC-2055) was the most dissimilar with each of G15 (A.E.D.), G18 (Midland), G19 (Reid Type), G6 (SC-30N11), G3 (SC-101) and G14(TWC 360) genotypes, since G9 (SC-2055) showed the highest dissimilarity Euclidean coefficients with these genotypes; so these pairs of genotypes are the most unrelated genotypes. Such dissimilarity suggests that inbred lines isolated from the F2 of SC-2055 might show good heterosis when crossed with those inbreds isolated from the populations of the other genotypes (A.E.D., Reid Type, Midland, F2 of SC-30N11, SC-101 or TWC 360).

On the contrary, dissimilarity Euclidean distances showed that the most related genotypes based on phenotypic data; i.e. those showed the lowest dissimilarity Euclidean coefficients, were the pair of genotypes G18 (Midland population) and G19 (Reid Type population) followed by the pair of genotypes G8 (SC-176) and G16 (Giza-2 population), the pair of genotypes G11 (TWC321) and G16 (Giza-2 population); the pair of genotypes G10 (TWC-310) and G11 (TWC-321); and the pair of genotypes G10 (TWC-310) and 
Table 6. Dissimilarity Euclidean coefficients based on phenotypic traits analysis among 19 maize genotypes (Combined across 6 environments)

\begin{tabular}{|c|c|c|c|c|c|c|c|c|c|c|c|c|c|c|c|c|c|c|}
\hline & G1 & G2 & G3 & G4 & G5 & G6 & G7 & G8 & G9 & G10 & G11 & G12 & G13 & G14 & G15 & G16 & G17 & G18 \\
\hline G2 & 126 & & & & & & & & & & & & & & & & & \\
\hline G3 & 70.9 & 172 & & & & & & & & & & & & & & & & \\
\hline G4 & 70.4 & 60.1 & 116 & & & & & & & & & & & & & & & \\
\hline G5 & 52 & 172.2 & 75.6 & 115.1 & & & & & & & & & & & & & & \\
\hline G6 & 59.9 & 180.7 & 77 & 125.9 & 35.8 & & & & & & & & & & & & & \\
\hline G7 & 64.6 & 97.6 & 114.9 & 49.1 & 91.2 & 103.7 & & & & & & & & & & & & \\
\hline G8 & 42.1 & 130 & 85.6 & 74 & 52.6 & 72.7 & 51.3 & & & & & & & & & & & \\
\hline G9 & 143 & 33.5 & 195.1 & 85 & 189.2 & 195.3 & 116.7 & 147.9 & & & & & & & & & & \\
\hline G10 & 37.3 & 138 & 88.6 & 82.4 & 38.9 & 60.7 & 54.9 & 25.2 & 154.9 & & & & & & & & & \\
\hline G11 & 28.7 & 117.9 & 87.6 & 61.7 & 55.6 & 72.7 & 42.7 & 26.8 & 136.3 & 21.9 & & & & & & & & \\
\hline G12 & 52.2 & 134.4 & 107.8 & 83.5 & 54.2 & 78.4 & 54.9 & 35.8 & 150 & 22.1 & 30 & & & & & & & \\
\hline G13 & 84.8 & 155.4 & 118.2 & 104.1 & 72.1 & 95.8 & 62.8 & 53.3 & 174.2 & 51 & 61.2 & 48 & & & & & & \\
\hline G14 & 80.6 & 170.3 & 98.9 & 114.1 & 56.3 & 81.2 & 77.7 & 55.1 & 191.1 & 50.8 & 64.3 & 56.5 & 29.1 & & & & & \\
\hline G15 & 90.5 & 189.1 & 113.7 & 134.4 & 51.7 & 77 & 97.5 & 66.6 & 206.1 & 57.5 & 77.4 & 60 & 45.5 & 34.3 & & & & \\
\hline G16 & 35.6 & 116.8 & 80.7 & 58.7 & 61.3 & 76.6 & 40.4 & 20.1 & 136.7 & 31.9 & 21.2 & 43.9 & 61.3 & 63.5 & 80.5 & & & \\
\hline G17 & 45.6 & 122.9 & 71.7 & 63.4 & 65.8 & 83.4 & 48.9 & 33.7 & 146.7 & 43.3 & 34.4 & 55.2 & 61.6 & 58.5 & 82.6 & 22.3 & & \\
\hline G18 & 104 & 184.5 & 124.4 & 132 & 75.6 & 100.6 & 92.6 & 70.8 & 203.1 & 69.5 & 84.9 & 69.2 & 32.6 & 31.6 & 32.5 & 82.9 & 81.9 & \\
\hline G19 & 104 & 185.6 & 127.7 & 133.4 & 76 & 101.5 & 93.5 & 73.9 & 204 & 69.6 & 85.2 & 67.7 & 31.5 & 31.8 & 30.6 & 85.6 & 84.4 & 13.7 \\
\hline
\end{tabular}


G12 (TWC-1100); they are the most related genotypes in this experiment. These results indicate that the two populations Reid Type and Midland might have a common ancestor (both of them are of USA origin). Moreover, one or more inbred parents of the SC-176 (G8) or TWC-321 (G11) might come from the synthetic population Giza-2 (G16), since they were among the most related pairs of genotypes in this experiment based on the dissimilarity Euclidean distances. Also, the two hybrids TWC-310 and TWC-321 were closely related based on the dissimilarity Euclidean distances, suggesting that these two hybrids might have common ancestor in the breeding program of ARC-Egypt.

\subsection{Agglomerative Hierarchical Clustering (AHC) Analysis}

Morphological traits, involving principal component analyses, are also commonly used in genetic diversity estimates. Principal component analyses of morphological traits (Table 6) found that the first principal component, which explained $32.39 \%$ of the total variability among genotypes, contrasted grain protein, grain fiber, and grain ash contents, anthesis-silking interval and rows/ear with the grain yield, 100-kernel weight, NUE, kernels/row, grain moisture content and NUTE. The result implies that cultivars characterized by short ASI and low protein, fiber and ash content were higher yielding, kernel weight and number, nitrogen use and utilization efficiency. Moreover, the $1^{\text {st }}$ principal component indicated the joint importance of GYPP, NUE followed by $100-$ kernel weight, ears/plant, grain $\mathrm{N}$, anthesis-silking interval, plant height, and ear height in discriminating maize cultivars and populations. The second principal component explained $25.22 \%$ of the total variability and indicated the joint importance of grain starch content, grain moisture content, grain protein content, days to silking and to anthesis, NUTE and $\mathrm{CCl}$, in the discrimination of maize genotypes (Table 5).

The clustering pattern of the maize genotypes generated from the standardized morphological data across stressed and non-stressed environments using complete linkage method is depicted in Fig. 2. The analysis assigned the 19 genotypes into four groups. Group1 included two genotypes; namely G2 (Pioneer-Corteva cultivar SC-30K8) characterized by high grain yield, number of grains/row, grain oil content, NUTE and NUE and the Hi-Tec cultivar G9 (SC-2055) characterized high grain yield, grain number/plant and grain fiber content, but these two genotypes were among the most distant genotypes (Table 4).

The second group include five genotypes (G13, G14, G15, G18 and G19) grouped together which had low-yielding, low NUE, short plant, low ear height, high grain fiber and ash content, long ASI; they were closely interrelated genotypes. The first group is widely distant from the second group.

The third group included three genotypes located in two sub-groups; the first sub-group included the Fine Seed cultivar only SC-101 (G3) which is the best genotype in this experiment for high GYPP, NUE, NUTE, 100-KW, GN, low ash and fiber, and early in DTS. The second sub-group of the third group included the two genotypes G5 (Hi-Tec cultivar SC-2031) and G6 (PioneerCorteva cultivar SC-30N11) grouped together which had average GYPP, high protein, GN, EPP, $\mathrm{PH}, \mathrm{CCl}$, late DTS, low KPP and grain moisture content; they were closely related genotypes.

The fourth group includes nine genotypes, seven of them are bred by ARC-Egypt and sub-divided into three sub-groups; the 1st sub-group included G4 (SC-131) and G7 (SC-168); both of them had high GN, but they differ in protein and NUTE; where G7 had high protein and low NUTE but G4 had low protein and high NUTE. G4 (SC-131) and G7 (SC-168) were closely related genotypes. The 2 nd sub-group included the three genotypes G10 (TWC-310) from ARC, Egypt, G11 (TWC-321) from ARC, Egypt and G12 (TWC-1100) from Hi-Tec; they are very closely related with respect of the morphological traits. The 4th sub-group included four genotypes; G1 (SC-10) in one separate sub sub-group, G17 (Nubaria population) in the 2 nd sub sub-group and G8 (SC-176) and G16 (Giza-2 population) in the 3rd sub sub-group. G8 and G16 were the most closely related genotypes.

\section{DISCUSSION}

The present study investigated 19 maize genotypes (14 Egyptian hybrid cultivars and five populations) by 21 phenotypic traits. Although morphological analysis for genetic diversity assessment presents many limitations as low polymorphism and influence of environment on phenotypic expression [34], phenotypic traits were helpful as a preliminary evaluation of maize genetic diversity and provided practical and critical information required to characterize genetic resources [35,36]. 


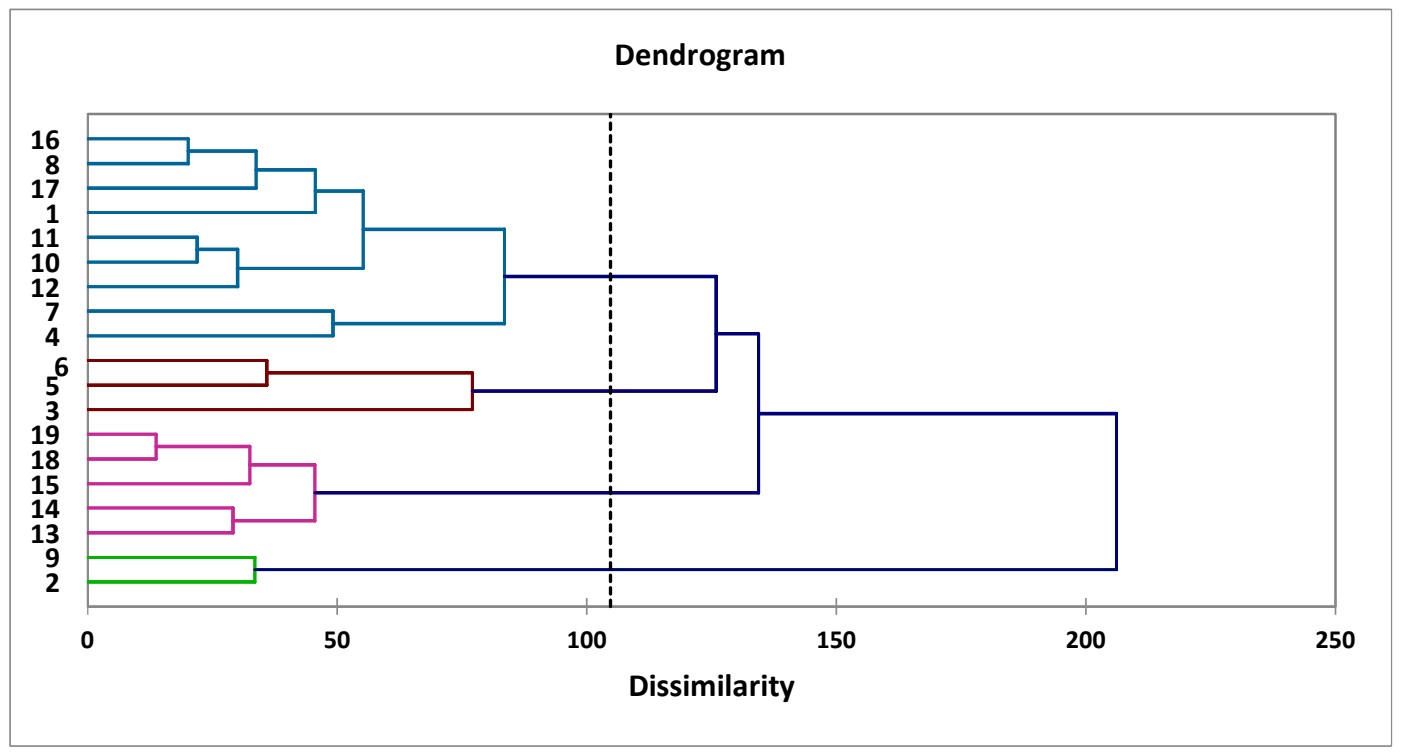

Fig. 2. Dendrogram of 19 maize genotypes based on 21 morphological characters measured across six stressed and non-stressed environments using the average method of clustering

Morphological traits measured (21 traits) depicted significant $(P \leq 0.01)$ differences among the maize hybrids and populations. Variation for most of the traits was observed. Morphological traits are very important for grouping corn genetic resources, and also are essential and useful for plant breeders seeking to improve existing germplasm by introducing novel genetic variation for certain traits into the breeding populations [5, 37-40]. They reported the existence of substantial variability in different gene pools of maize germplasm.

Coefficient of variation (CV) was generally very low $(<10 \%)$ for most of studied traits, indicating good accurcy of the experiment. The exceptions were ASI, GMC, GOC and GFC, where CV was $32.8,20.67,16.69$ and $21.92 \%$, respectively. The large coefficients of variability in this study for anthesis-silking interval were comparable to other investigators $[37,38]$.

The high phenotypic variability was observed, particularly for the agronomic traits ASI, NUE, GYPP, CCI, KPP and 100-KW and the grain quality traits grain oil and fiber contents. Sultana [41] also determined highly significant differences for these traits. Sharma et al. [42] observed significant differences among 20 maize genotypes for days to $50 \%$ flowering, cob length, plant height, 100 grain weight, grain yield per plant and stalk weight. Saeed et al. [43] found significant differences among genotypes provided by CIMMYT and local checks for all traits except ear height. Such high variability suggested that the germplasm was adapted to a wide range of environmental conditions, and could provide valuable alleles for maize improvement $[40,44]$.

Variability in ASI, NUE and GYPP was about six to seven fold larger than variability in DTA and DTS, in the studied cultivars and populations of maize. Such a large phenotypic diversity this much, reflects the differential fitness to the environment, flexibility and survival in changing environmental conditions. The data obtained will guide parental selection for maize improvement and broadening of the genetic base of breeding populations $[38,39]$. The presence of genetic variability among the genotypes for grain yield and other agronomic traits under drought or low $\mathrm{N}$ stress and no stress conditions indicated that significant progress could be made in selecting for improved grain yield and other traits under stressed and no stressed conditions [45].

The highest GYPP, 100-KW, GSC and NUTE were shown by the genotype G3, while the highest grain protein content, grain oil content, ears/plant and the shortest ASI were recorded by G7, G2, G6 and G5, respectively. Genotype G2 was also the best in NUE and kernels/row. These genotypes might possess favorable genes that could be exploited to improve Egyptian maize for the respective traits. 
Various studies have employed multivariate statistical analysis such as principal component analysis (PCA) to evaluate the magnitude of genetic diversity among the crop germplasm [46, 47] and to reduce a large number of observed traits into a smaller set of traits that have the maximum contribution in separating the genotypes. The PCA was performed to classify the hybrids and populations on the basis of the most discriminating traits. Our results revealed two main components accounting for $57.91 \%$ of total variability. Generally, the contribution of PC1 for the 21 traits were 1.3 fold more than that of PC2. Bin Mustafa et al. [48] stated that 59.3 and $55 \%$ of the total variation were contributed by the first two PCs when evaluating maize genotypes at 100 and $40 \%$ moisture levels. PCA showed that the three factors had eigenvalue $>$ 1 , moreover 56.13 and $57.2 ; 56.22$ and $58.94 \%$ of the total variability were explained by the first two PCs under the same conditions. Others recorded two PCs that contributed to $94.01 \%$ and $91.15 \%$ of total variation in root traits of 103 maize inbred lines evaluated in control and water-stressed conditions [49]. Suryanarayana et al. [50] applied PCA and cluster analysis to data for 30 maize accessions in India. In their study the first five PCs had eigenvalues greater than 1, which collectively explaining $85.31 \%$ of the variance. They identified days to $50 \%$ anthesis, ear length and number of kernels per row as the factors that made the greatest contributions to total variance. Pahadi et al. [51] found eigenvalues greater than 1 for their first two PCs, which explained $73.7 \%$ of the variance. They noted that days to $50 \%$ anthesis was the most influential trait. Ali et al. [52] found eigenvalues greater than 1 for their first three PCs, which accounted for $89.60 \%$ of the variance in maize hybrids grown in Pakistan. Kumari et al. [5] found that the first two principal components explained more than $50 \%$ of the phenotypic variation among collected landraces and traditional cultivars of maize. Saeed et al. [43] found four PCs had eigenvalues greater than 1 and explained $73.38 \%$ of the total variance in maize genotypes provided by CIMMYT and in local checks in Pakistan.

Biplot in the principal component represents variables that are super imposed on a plot as vectors where relative length of vectors represents the relative proportion of variability in each variable represented on biplot [41]. The results of the GT biplot analysis revealed that among the traits analyzed, grain yield/plant, NUE followed by 100-kernel weight, ears/plant, rows/ear, grain $\mathrm{N}$, anthesis-silking interval, plant height, ear height, played a crucial role in differentiating the hybrids and populations, as they had relatively long vectors. In other words, they are the most discriminator of the morphological data under study. On the contrary, kernels/row, kernels/plant, grain ash content and grain oil content were the least discriminator, as they had relatively short trait vectors, indicating that they may be less important in evaluating maize genotypes for drought/low $\mathrm{N}$ tolerance. The PCA-based grouping of Egyptian maize germplasm is in agreement with those obtained by several authors $[36,53,54]$, who reported that plant height and ear height, ear length and yield were the most discriminating traits to identify maize populations in Eastern Serbia and Mexico, respectively.

The knowledge of interrelationships between grain yield and its associated traits will improve the efficiency of breeding programs through the use of appropriate selection indices [45]. The small acute angle observed between grain yield and each of NUE, 100-KW, EPP, PH, KPP, KPR, NUTE, and GN (Fig. 1) indicated the existence of very strong positive correlations between grain yield and such traits and that improvement in these traits would contribute to significant progress in grain yield under water/nitrogen stressed and non-stressed conditions. Similarly, the existence of negative correlations between grain yield and anthesis-silking interval (ASI), grain protein content, RPE and GFC under water/nitrogen stressed and non-stressed conditions indicate that these traits might have direct or indirect effects on grain yield under these conditions. These results justified the inclusion of most of these traits in the base index for selection of genotypes for tolerance to drought and or low N stresses. Several studies have identified yield components as strong secondary traits for yield improvement under drought/low $\mathrm{N}$ stress due to the strong genetic correlations with yield under stress conditions. On the contrary, results of the GT biplot in the present study indicated that short ASI was the most reliable secondary trait for improving grain yield under stressed and non-stressed conditions. These results are in agreement with those reported by earlier investigators [45,55-61]. These results corroborated the findings of Aci et al. [44], who reported that maize landraces characterized by short ASI were the most productive. An ASI period of 2-4 days is considered ideal for drought tolerance [62]. Results by Ziyomo and Bernardo [63] recorded 
negative correlations of ASI with YP and $\mathrm{PH}$. The study by Monneveux et al. [64] suggested that selection for bigger grains and smaller tassels may help to increase grain yield in water-limited environments in the near future.

Cluster analysis is a method used in grouping a set of characters into clusters. Genotypic clustering makes use of a procedure called Agglomerative Hierarchical Clustering (AHC) using Unweighted Pair Group Method with Arithmetic mean (UPGMA) [20]. Cluster analysis is one of the statistical techniques aimed at grouping objects in clusters so that the objects in one cluster have high similarities than those in other clusters [65]. Euclidian distance values in the range of $0-1$ indicates a small dissimilarity, whereas, its value more than 1 indicates a large dissimilarity coefficient. A small dissimilarity coefficient indicates that for each genotype one or the other characters have a narrow variability [66]. Cluster analysis for 19 maize genotypes using 21 morphological traits is presented in Fig. 2. The analysis assigned the 19 genotypes into four groups. The clusters represent uncorrelated groups which may be useful for future heterotic breeding as their trait performance may be governed by different sets of alleles [38].

The highest genetic distance was found between G9 (SC-2055) and each of G15 (A.E.D.) and G18 (Midland) followed by G19 (Ried Type), since they showed the highest dissimilarity Euclidean coefficients (Table 6). Such dissimilarity suggests that inbred lines isolated from the F2 of the single cross SC-2055 might show maximum heterosis when crossed with those inbreds isolated from either A.E.D., Midland or Ried Type populations. On the other hand, the lowest genetic distance was found between the maize genotype G18 (Midland population) and G19 (Reid Type population) in the same group, since they showed the lowest dissimilarity Euclidean coefficients. These two populations might have a common ancestor (both of them are of USA origin).

The partitioning of the hybrids and populations into clusters suggests that benefits would be accrued from intercrossing between clusters to exploit heterosis for grain yield, and other desirable traits, such as short ASI which indicate less sensitivity to drought or low $\mathrm{N}$ stress. A within cluster crossing involving a large number of ears should preserve the rare alleles in the collection [67]. He added that the combined high yield and early-maturity traits present novel genes at these loci and may be beneficial for broadening the genetic base of elite gene pools.

The results of the present study clearly revealed significant phenotypic diversity of the Egyptian maize hybrids and populations. Furthermore, this diversity among maize hybrids and populations could be related to different plant response to different environments. Therefore, these promising maize hybrids and populations could be potentially utilized for the introgression of adaptive traits, which may be found in extreme environments [36]. The distribution of hybrids and populations into morphologically similar groups should quicken the usefulness of these data to maize breeders.

\section{CONCLUSION}

Multivariate statistical analysis such as principal component analysis (PCA) of morphological data was able to assess genetic diversity, describe and classify a collection of 19 maize Egyptian cultivars and populations. Our data showed substantial variation in morphological traits among these genotypes. The genotype $\times$ trait (GT) biplot method allowed easy and better assessment of correlations between the traits and identified the reliable secondary traits for improving grain yield under water and/or low $\mathrm{N}$ stressed and non-stressed conditions. The Agglomerative Hierarchical clustering based on morphological data was able to identify the most unrelated hybrids and populations to be used as parents for isolating inbred lines when crossed would show maximum heterosis. This information will be useful for identifying genotypes for broadening the genetic base in the gene pools of maize improvement programs. Further investigations should be undertaken for collection, characterization and utilization of Egyptian and exotic maize germplasm.

\section{COMPETING INTERESTS}

Authors have declared that no competing interests exist.

\section{REFERENCES}

1. FAOSTAT. FAOSTAT Database. Rome: FAO.

(Accessed 17 December 2019) Available:http://faostat.fao.org 
2. Gerpacio VR, Pingali PL. Tropical and subtropical maize in Asia: Production systems, constraints and research priorities. CIMMYT Mexico. 2007;93.

3. Mustafa HSB, Aslam M, Hasan EU, Hussain F, Farooq J. Genetic variability and path coefficient in maize (Zea mays L.) genotypes. The Journal of Agricultural Sciences 2014;9(1):37-43.

4. Zubair M, Ajmal SU, Anwar M, Haqqani M. Multivariate analysis for quantitative traits in mungbean [Vigna radiata (L.) Wilczek]. Pak. J. Bot. 2007;39:103-113.

5. Kumari J, Kumar A, Singh TP, Bhatt KC, Mishra AK, Semwal DP, Sharma RK, Rana JC. Collection, evaluation and phenotypic diversity assessment of maize (Zea mays) germplasm from North Eastern Himalayan region. Indian Journal of Agricultural Sciences 2017;87(6):727-33.

June 2017/Article.

6. Dao A, Sanou J, Mitchell SE, Gracen V, Danquah EY. Genetic diversity among INERA maize inbred lines with single nucleotide polymorphism (SNP) markers and their relationship with CIMMYT, IITA, and temperate lines. BMC Genetics. 2014; 15(1):1.

7. Legesse BW, Myburg AA, Pixley KV, Botha AM. Genetic diversity of African maize inbred lines revealed by SSR markers. Hereditas 2007;144:1017.

Available:https://doi.org/10.1111/j.2006.00 18-0661.01921.x

8. Cholastova T, Soldanova M, Pokorny R. Random amplified polymorphic DNA (RAPD) and simple sequence repeat (SSR) marker efficacy for maize hybrid identification. African Journal of Biotechnology. 2011;10(24):4794-4801.

9. Botha AM, Venter E. Molecular marker technology linked to pest and pathogen resistance in wheat breeding. South Afr. J. Sci. 2000;96:233-240.

10. Prasanna B M and Sharma L. The landraces of maize (Zea mays L.) diversity and utility. Indian Journal of Plant Genetic Resources. 2005;18:155-68.

11. Wasala S K, Guleria SK, Sekhar JC, Mahajan V, Srinivasan K, Parsad R, Prasanna BM. Analysis of yield performance and genotype $\times$ environment effects on selected maize (Zea mays) landrace accessions of India. Indian
Journal of Agricultural Sciences 2013;83: 287-93.

12. Govindaraj $M$, Vetriventhan $M$, Srinivasan M. Importance of genetic diversity assessment in crop plants and its recent advances: An overview of its analytical perspectives. Genet. Res. Int. 2015; 431487.

13. Mengistu DK, Afeworki YK, Mario EP. Phenotypic Diversity in Ethiopian Durum Wheat (Triticum turgidum Var. Durum) Landraces. The Crop Journal 2015;3:190-199.

DOI:10.1016/j.cj.2015.04.003

14. Salazar E, Correa J, Araya MJ, Marco AM, Carrasco B. Phenotypic diversity and relationships among chilean choclero maize (Zea mays L.) landraces. Plant Genetic Resources 2016;15: 461-473. DOI:10.1017/S1479262116000137

15. Sattler FT, Sanogo MD, Kassari IA, Angarawai II, Gwadi KW, Dodo $\mathrm{H}$, Haussmann BIG. Characterization of West and Central African Accessions from a pearl millet reference collection for agromorphological traits and striga resistance. Plant Genetic Resources 2018;16:260272.

DOI:10.1017/S1479262117000272

16. Yadav RK, Gautam S, Palikhey E, Joshi BK, Ghimire KH, Gurung R, Dhakal R. Agro-morphological diversity of nepalese naked barley landraces. Agriculture and Food Security 2018;7:86.

DOI:10.1186/s40066-018-0238-5

17. Tiwari DN, Tripathi SR, Tripathi MP, Khatri N, Bastola BR. Genetic variability and correlation coefficients of major traits in early maturing rice under rainfed Lowland environments of Nepal. Advances in Agriculture 2019;1-9.

DOI:10.1155/2019/5975901

18. Ajmal SU, Minhas NM, Hamdani A, Shakir A, Zubair M, Ahmad Z. Multivariate analysis of genetic divergence in wheat (Triticum aestivum) germplasm. Pak. J. Bot. 2013;45:1643-1648.

19. Malik R, Sharma H, Sharma I, Kundu S Verma A, et al. Genetic diversity of agromorphological characters in Indian wheat varieties using GT biplot. Aust. J. Crop Sci. 2014;8:1266-1271.

20. Mohammadi SA, Prasanna BM, Singh NN. Sequential path model for determining 
interrelationships among grain yield and related characters in maize. Crop Sci. 2003;43:1690-1697.

21. Babic V, Pajic Z, Prodanovic S, Babic M, Filipovic M. Visual assessment of sweet maize lines phenotype, according to UPOV descriptor, as indicator of heterosis. Genetika. 2010;42:313-322.

22. Azad MAK, Biswas BK, Alam N, Alam SS. Genetic diversity in maize (Zea mays L.) inbred lines. Agriculturists 2012;10:6470.

23. De Leon $\mathrm{N}$, Jannink JL, Edwards JW, Kaeppler SM. Introduction to a special issue on genotype by environment interaction. Crop Science 2016;56(5): 2081-2089.

24. Yan W. Crop variety trials: Data management and analysis. WileyBlackwell, Hoboken, New Jersey, USA. 2014;349.

25. Dehghani H, Dvorak J, Sabaghnia N. Biplot analysis of salinity related traits in beard wheat (Triticum aestivum L.) Annals Biological Research 2012;3:3723-3731.

26. Akcura $M$, Kokten $\mathrm{K}$. Variations in grain mineral concentrations of Turkish wheat landraces germplasm. Quality Assurance and Safety of Crops \& Foods. 2017; 9(2):153-159.

27. Yan W, Frégeau-Reid J, Pageau D, Martin $\mathrm{R}$, Mitchell-Fetch J, Etienne $\mathrm{M}$, et al. Identifying essential test locations for oat breeding in eastern Canada. Crop Science 2010;50(2):504-515.

28. Mohammadi R, Amri A. Genotype $\times$ Environment interaction implication: A case study of durum wheat breeding in Iran. In Al-Khayri, J.M., Jain, S.M., and Johnson, D.V. (eds.) Advances in plant breeding strategies: Agronomic, abiotic and biotic stress traits. Springer, Cham, Switzerland. 2016;(Chapter14):515-558.

29. Steel RGD, Torrie JH, Dickey DA. Principles and Procedures of Statistics. 3rd Edition. New York, McGraw-Hill; 1997.

30. Yan W, Hunt LA, Sheng Q, Szlavnics Z. Cultivar evaluation and mega-environment investigation based on GGE biplot. Crop Sci. 2000;40:597-605.

31. Yan W, Tinker NA. An integrated system of biplot analysis for displaying, interpreting, and exploring genotype by environment interactions. Crop Sci. 2005;45:10041016.
32. Addinsoft. XLSTAT statistical and data analysis solution. Boston, USA; 2014. Available:http://www.xlstat.com

33. Yan W, Rajcan I. Biplot evaluation of test sites and trait relations of soybean in Ontario. Crop Sci. 2002;42:11-20.

34. Beyene $\mathrm{Y}$, Botha AM, Myburg AA. A comparative study of molecular and morphological methods of describing genetic relationships in traditional Ethiopian highland maize. Afr J Biotechnol. 2005; 4:586-595.

35. Ignjatovic-Micic D, Ristic D, Babic V, Andjelkovic V, Vancetovic J. A simple SSR analysis for genetic diversity estimation of maize landraces. Genetika 2015;47:5362.

36. Belalia N, Lupini A, Djemel A, Morsli A, Mauceri A, Lotti C, Khelifi-Slaoui M, Khelifi $L$, Sunseri F. Analysis of genetic diversity and population structure in Saharan maize (Zea mays L.) populations using phenotypic traits and SSR markers. Genet Resour Crop Evol. 2019;66:243257.

Available:https://doi.org/10.1007/s10722018-0709-3

37. Asare S, Tetteh AY, Twumasi P, Adade $\mathrm{KB}$, Akromah R. Genetic diversity in lowland, Mid-altitude and highland African maize landraces by morphological trait evaluation. African Journal of Plant Science 2016;10:246-257.

DOI:10.5897/AJPS2016.1448

38. Twumasi P, Tetteh AY, Adade KB, Asare S, Akromah R. Morphological Diversity and Relationships among the IPGRI Maize (Zea mays L.) Landraces Held in IITA. Maydica. 2017;62:1-9.

39. Salami HA, Sina H, Wallis NZ, Padonou W, Yallou C, Chabi-Sika K, Noumavo PA, Aly D, Adjanohoun A, Baba-Moussa L. Agromorphological Variability of Zea mays (L.) Accessions Collected in Southern Benin. Journal of Plant Breeding and Crop Science 2017;9:1-9. DOI:10.5897/JPBCS2016.0619

40. Nelimor C, Badu-Apraku B, Simon P, Nguetta A, Antonia TY, Garcia-Oliveira Ana L. Phenotypic characterization of maize landraces from Sahel and Coastal West Africa reveals marked diversity and potential for genetic improvement. Journal of Crop Improvement; 2019.

DOI: 10.1080/15427528.2019.1674760 
41. Sultana R. Molecular and Morphological Characterization of Maize Genotypes for Opaque 2 Gene and Yield Contributing Traits. Big Data in Agriculture. 2019;1(1): 03-10.

42. Sharma M, Singh O, Singh G, Kaur G. A snap shot of spring maize cultivation in kapurthala and jalandhar districts under central plain zone of Punjab. Journal of Krishi Vigyan 2014;3(1):1-4.

43. Saeed M, Mumtaz A, Hussain D, Arshad M, Yousaf MI, Ahmad MS. Multivariate analysis based evaluation of maize genotypes under high temperature stress. I3 Biodiversity. 2018;1:105.

44. Aci MM, Lupini A, Maugeri A, Morsli A, Khelifi L, Sunseri F. Genetic Variation and Structure of Maize Populations from Saoura and Gourara Oasis in Algerian Sahara. BMC Genetics 2018;19:51. DOI:10.1186/s12863-018-0655-2

45. Oyekunle M, Badu-Apraku B. Assessment of interrelationships among grain yield and secondary traits of early-maturing maize inbred lines under drought and wellwatered conditions. Maydica electronic publication. 2018;63 M18:1-10.

46. Brown-Guedira G.L. Evaluation of genetic diversity of soybean introductions and North American ancestors using Rapd and SSR markers. Crop Science. 2000;40:815823

47. Wijewardana $\mathrm{CH}$, Hock M, Henry B, Reddy KR. Screening corn hybrids for cold tolerance using morphological traits for early-season seeding. Crop Science. 2015; 55:851-867.

48. Bin Mustafa HS, Farooq J, Ul-Hasan E, Bibi1 T, Mahmood T. Cluster and principle component analyses of maize accessions under normal and water stress conditions. Journal of Agricultural Sciences 2015;60: 33-48.

49. Li R, Zeng Y, Xu J, Wang Q, Wu F, Cao M, Lan $\mathrm{H}$, Liu $Y$. Genetic variation for maize root architecture in response to drought stress at the seedling stage. Breeding Science. 2015;65:298-307.

50. Suryanarayana L, Sekhar MR, Babu DR, Ramana AV, Rao VS. Cluster and principal component analysis in maize. International Journal of Current Microbiology and Applied Sciences. 2017; 6(7):354-359.

51. Pahadi P, Sapkota M, Thapa DB, Pradhan S. Cluster and principal component analysis for the selection of maize (Zea mays L.) genotypes. International Journal of Experimental Research and Review. 2017;9:5-10.

52. Ali F, Kanwal N, Ahsan M, Ali Q, Bibi I, Niazi NK. Multivariate analysis of grain yield and its attributing traits in different maize hybrids grown under heat and drought stress. Scientifica; 2015.

Article ID 563869.

Available:http://dx.doi.org/10.1155/2015/56 3869

53. Mijangos-Cortés J O, Corona-Torres $\mathrm{T}$, Espinosa Victoria D, Muñoz-Orozco A, Romero-Peñaloza J, Santacruz-Varela A. Differentiation among maize (Zea mays L.) landraces from the Tarasca Mountain Chain, Michoacan, Mexico and the Chalqueno complex. Genetic Resources and Crop Evolution. 2007;54:309-25.

54. Jaric $\mathrm{J} \mathrm{K}$, Prodanovic $\mathrm{S}$, Iwarsson $\mathrm{M}$, Minina A. Diversity of maize (Zea mays L.) landraces in Eastern Serbia: Morphological and storage protein characterization. Maydica. 2010;55:231-8.

55. Banziger M, Lafte HR. Effciency of secondary traits for improving maize for low-nitrogen target environments. Crop Sci. 1997;37:1110-1117.

56. Edmeades GO, Bolanos J, Chapman SC. Value of secondary traits in selecting for drought tolerance in tropical maize. In: Edmeades GO, Banziger $\mathrm{M}$, Mickelson HR, Pena-Valdivia CB (Eds.), Developing drought and low $\mathrm{N}$ tolerant maize. Proceedings of a Symposium, El Batan, Mexico. D.F; 1996. CIMMYT, El Batan, Mexico, D.F. 1997;222-234.

57. Badu-Apraku B, Akinwale RO, Ajala SO, Menkir A, Fakorede MAB, Oyekunle M. Relationships among traits of tropical early maize cultivars in contrasting environments. Agron J. 2011;103:717729.

58. Al-Naggar AMM, Shabana R, Atta MMM, Al-Khalil TH. Maize response to elevated plant density combined with lowered $\mathrm{N}$ fertilizer rate is genotype-dependent. The Crop Journal 2015;3:96-109.

59. Al-Naggar AMM, Shabana R, Abd-ElAleem MM, El-Rashidy Z. Mode of inheritance of low- $\mathrm{N}$ tolerance adaptive traits in wheat (Triticum aestivum L.) under contrasting nitrogen environments. Spanish Journal of Agricultural Research 2017;15(2):1-11. 
60. Al-Naggar AMM, Shafik MM, Elsheikh MOA. The Effects of Genotype, Soil Water Deficit and Their Interaction on Agronomic, Physiologic and Yield Traits of Zea mays L. Annual Research \& Review in Biology 2018;29(5):1-17.

61. Al-Naggar AMM, Shafik MM, Elsheikh MOA. Putative Mechanisms of Drought Tolerance in Maize (Zea mays L.) via Root System Architecture Traits. Annual Research \& Review in Biology. 2019; 32(2):1-19.

Available:https://doi.org/10.9734/arrb/2019 Iv32i230079.

62. Dass $S$, Arora $P$, Kumari M, Dharma $P$. Morphological traits determining drought tolerance in maize. India J, Agric. Res. 2001;35:190-193.

63. Ziyomo C, Bernardo R. Drought tolerance in maize: indirect selection through secondary traits versus genome wide selection. Crop Science 2013;52:12691275.

64. Monneveux $P$, Sanchez $C$, Tiessen A. Future progress in drought tolerance in maize needs new secondary traits and cross combinations. Journal of Agricultural Sciences 2008;146:287-300.

65. Sharma S. Applied multivariate techniques. 1st Edn, John Wiley and Sons Inc. New York; 1996.

ISBN: 0-47131064-6

66. Tairo F, Mneney E, Kullaya A. Morphological and agronomical characterization of sweet potato [Ipomoea batatas (L.) Lam.] germplasm collection from Tanzania. Afr. J. Plant Sci. 2008;2:77-85.

67. Crossa J. Methodologies for estimating the sample size required for genetic conservation outbreeding crops. Theor. Appl. Genet. 1989;77:153-161.

(c) 2020 Al-Naggar et al.; This is an Open Access article distributed under the terms of the Creative Commons Attribution License (http://creativecommons.org/licenses/by/4.0), which permits unrestricted use, distribution, and reproduction in any medium, provided the original work is properly cited.

Peer-review history:

The peer review history for this paper can be accessed here: http://www.sdiarticle4.com/review-history/56180 